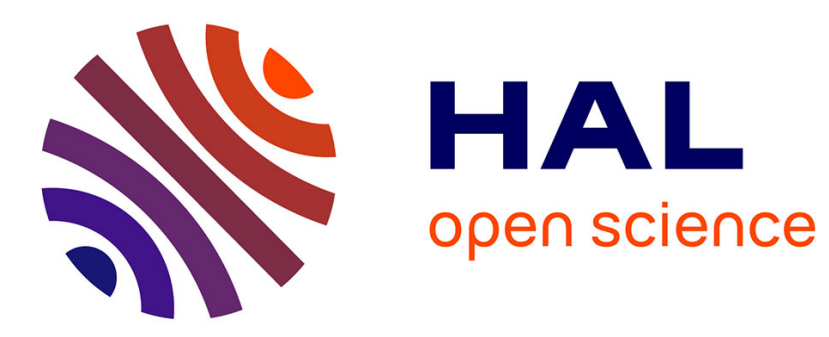

\title{
What else do students need?
}

Amanda Baker

\section{To cite this version:}

Amanda Baker. What else do students need?. Active Learning in Higher Education, 2006, 7 (2), pp.171-183. 10.1177/1469787406064751 . hal-00571946

\section{HAL Id: hal-00571946 \\ https://hal.science/hal-00571946}

Submitted on 1 Mar 2011

HAL is a multi-disciplinary open access archive for the deposit and dissemination of scientific research documents, whether they are published or not. The documents may come from teaching and research institutions in France or abroad, or from public or private research centers.
L'archive ouverte pluridisciplinaire HAL, est destinée au dépôt et à la diffusion de documents scientifiques de niveau recherche, publiés ou non, émanant des établissements d'enseignement et de recherche français ou étrangers, des laboratoires publics ou privés. 
A psychodynamic reflection on students'

\author{
need for support from staff at university
}

\author{
AMANDA BAKER University of Portsmouth
}

\begin{abstract}
This article considers university staff's place in students' worlds from a psychodynamic perspective. It looks at 'studenthood' as a psychological stage, in which relationship to university and university staff is seen as being recruited into a personal developmental context. It sketches some psychodynamic background for understanding the role students unconsciously assign to staff, in terms of concepts such as transference, projection and containment. It makes connections between mechanisms for early infancy social learning about self/identity and the identity-establishing responses which students need at their stage too. It uses this understanding to explain some of the difficulties which can be experienced in responding to troubled students. We can extrapolate from the more difficult end of the spectrum to inform our general understanding about the dynamics of students' need for responsiveness and 'help', and the article finally briefly considers 'help' and 'problems' as usually being developmental rather than pathological agents of students' learning process.

KEYWORDS: containing, developmental, problems, psychodynamic, relationship, responsiveness
\end{abstract}

\title{
Introduction
}

This article originated as a discussion paper for a Counselling Service-led workshop on the theme of 'responding to students' designed for a group of mostly academic staff at the University of Portsmouth. The aim of that paper was to facilitate, using a psychodynamic perspective, an understanding of some of the experiences staff might be having of students' impact, needs and demands. The staff group wanted help with their effectiveness in their own jobs, rather than to learn how to provide counselling, and a question they brought was how academic staff who are sensitive listeners and empathetic people can respond constructively to needy students without becoming enmeshed in escalating cycles of 
dependency which exceed the boundaries of, and sometimes undermine the function of, the academic-to-student relationship.

What follows is a description of 'studenthood' as a developmental stage, explained with reference to the psychological mechanisms of development of self in infancy, since it is suggested that these same mechanisms - underpinned by crucial dynamic relationships with caregivers - extend onward into later developmental processes especially at times of transition. It is suggested here, in line with O'Carroll (1997), Percy (2001) and others, that a student's relationship with the university can play a dynamic part in their present personal development. The article looks at studenthood from the stance of staff as participant observers: viewing the de facto existence of students' relationship with the university and with staff as both a useful litmus for what is happening in students' internal worlds and a vehicle for some sort of delivery of help. (It is worth remembering that most students, in spite of major challenges, weather and negotiate this stage without needing too much help.) Using psychodynamic concepts, the article goes on to consider the ways in which the personal 'baggage' carried by those students who do encounter major difficulties can obstruct the very relationships they turn to for help, posing questions about how, in spite of this, we can resolve such distortions enough to access the potential of the relationship to be helpful. This leads to the suggestion that this process of encountering and dealing with snags is in itself frequently a developmental rather than pathological one, lying at the very heart of the mechanism for healthy learning, whether psychological or academic. For this reason it is argued that a holistic and integrated approach to supporting students can have benefits which may be lost with an over-compartmentalizing 'specialist' approach.

This article does not seek to answer the question about what to do, but reflects on what is happening when staff feel their involvement in student difficulties to be uncomfortable. The students whom staff find the most challenging are likely to be those who themselves are feeling anxious, challenged and unable to manage their own difficult feelings unaided. The aim here is to introduce a psychodynamic understanding of the experience of becoming a student, and to suggest how this could be useful to staff in their interactions with emotionally needy students. In contrast to the more secure students, the focus is on those whose impact on us feels more difficult, needy, or anxiety-provoking. While the more secure will confidently absorb and manage their difficulties, tending to be good at dialogue, able to negotiate, able to accept compromise, able to see different perspectives, and able to solicit, receive and consider advice appropriately, the latter group will be on the lookout for help with managing or resolving their own inability to manage and resolve things. The request for help with a 
crisis of the moment serves as the carrier for a more unconscious plea for a deeper sort of help.

In responding, it is helpful to be aware of how someone's personal backdrop profoundly influences their present responses, so newlyencountered difficulties such as course problems, relationship issues, crises in their student houses, losses, illnesses or bereavement are all experienced partly in terms of a background history. The 'local' problem can often be a facet of a backdrop problem, and longstanding difficulties will often be re-expressed in unconsciously generated local crises, via a well-worn, circular, compounding response-style. It is important to understand how background and foreground may be connected, and to be aware that background can become articulated in the neediness which appears in some students' relationships with staff at university. A psychodynamic perspective offers some explanation of this process.

To clarify, 'psychodynamic' is a term applied to a model of counselling and psychotherapy whose theory and clinical practice broadly derive from psychoanalysis. In common with psychoanalysis, psychodynamic work understands someone's present in the context of their past and its influence on their development. It focuses particularly on relationship, including the way a client forms relationship with the counsellor, and places importance on an awareness of the significant part played by the unconscious and the involuntary in our sense of ourselves and our sense of other people. Like psychoanalysis, psychodynamic counselling maintains that some of our difficulty in onward growth and learning is due to our defensive intolerance of states of confusion, disintegration, and not knowing. If we can bear the difficult feelings it engenders in us (both as clients and as helpers), a process of unlearning and unravelling can precede fresh discovering of our capacity for change and growth. In psychodynamic counselling, students often find it helpful to have the opportunity to pause and learn to be less frightened by their sense of uncertainty and inexperience in an environment which tends to foster a goal-directed trajectory towards knowing, achieving and succeeding.

With its focus on the mechanisms of change, a psychodynamic framework is found by many counsellors to be useful in understanding and supporting students as they negotiate this major point of transition and change in their lives. This framework has found a natural place within many university counselling services in Britain, tapping into processes common to both academic and personal learning. Aspects of counselling theory and practice (psychodynamic along with other models) can also be applied in a wider context than counselling itself, via the other 'scaffolding' relationships in students' lives. Hence the workshops for academic staff which counselling services sometimes offer, and the genesis of this article. 


\section{Studenthood}

Three ubiquitous underlying contributors to student stress are:

- Their role at university and their relationship with university in terms of autonomy/dependency.

- Their developmental stage of life.

- Circumstantial transition and change.

By looking at these in turn, we may identify elements of the transition to studenthood which are easily overlooked, but which are yet central to an effective staff-student relationship.

\section{Role at university - autonomy/dependency}

University students are in an odd position, on the cusp between dependence and independence. A growing child increasingly takes on the task of regulating things for him- or herself, shifting into the driver's seat as she or he becomes better able to predict what goes on both inside and outside, what influence she or he has over things, how to 'work the controls', and also how to manage the discomfort of not having control over some major aspects of his or her experience. By the time we see students, they are moving into a new phase in which they need to establish adult autonomy and self-determination, and need to be let go of by parents and adults around them. Yet by enrolling at university students subject themselves to what the less secure can perceive as the paradoxical indignity of a rather infantilizing compliance with an institutional - or 'adult' - demand that they be independent thinkers. We expect them to depend on us to help them become less dependent. They engage the university to teach, guide, assess and support them, and yet they are at a stage where their dignity and self-esteem depend on feeling that they have authorship of their own lives. Students have both childlike needs and very adult needs in an odd and often uneasy combination.

\section{Developmental stage of life}

Compounding this situation is the stressful effect of late adolescence as a developmental stage. (It is worth also noting that, while most students' age places them in late adolescence, many adults returning to study also find themselves revisiting an adolescent-type experience, in which they feel incapacitated in some ways, defined as being in deficit and needing to be taught and assessed by more fully endowed 'experts'. Mature students can also be seen as returning to late-adolescent tasks, such as redefining identity, 
dealing with separation, or establishing autonomy which they feel still unresolved in themselves. This thought originated from comments of Jim Pye, Mature Student Advisor at Oxford Brookes University in discussion in 2002-3.) 'Infantile' experiences are revisited and reworked, but this time with the psychological and physical strength and size of an adolescent. Late adolescence and the transition to adulthood are a time when our psychic configurations seem to loosen again, enabling very rapid changes and adjustments to be made (which some suggest can be an almost psychotic experience - an idea discussed by Stokoe, 2004). Volatility, unpredictability, uncertainty, and shifting and intensely held beliefs and ideas, are all part of the flavour of this experience. There is confusion about what to think, who one is, whether one likes or dislikes aspects of oneself. There is confusion about reading other people's responses too. And there is an Alice-inWonderlandish instability in the size of one's self-esteem: one feels big one moment and very small the next. The individual is making a bid to assert a distinctive identity, to be special in her or his own right, and to have more control, more autonomy or a different balance in her or his connections and ways of relating with people. And most of the students coming to university are still at an age and stage where this process is very alive.

During this stage, people are understandably self-conscious, sometimes rather narcissistically self-absorbed, and touchy about, as well as in need of, feedback from others about who they are, what they are like, what their impact is and what their value is. Adolescents need mirroring reflective feedback about themselves, in order to consolidate a viable identity. This process echoes and continues the work of building of self which, some would argue (Fonagy, 2001) is the principal preoccupation of infancy. It is now understood that the human baby is genetically primed to exist, survive, develop and unfold within a powerful environmental attachment bond with principal caregivers - usually one or two parents (Gerhardt, 2004; Holmes, 1996). This bond enables a baby to develop her or his sense of a self, including styles of behaviour, by discovering reflections of himor herself in the responsiveness of caregivers. If such responsiveness is experienced as being contingently elicited by the baby and therefore readable as a sort of analogue of him or her, and if this is comprehensibly congruent with internal senses and sensations, the baby can use it to catalyse a secure, acceptable, continuous and viable self which integrates inside and outside.

Since outside and inside are never identical, a developmental task is also to differentiate him- or herself from her surroundings. The child has to hold him- or herself intact and accommodate the separateness and difference between self and other by managing an interface between the child's own sense of things and the messages he or she receives from 
outside. There is a defining friction between self and outside, and this is manifest again in the differentiating behaviour we know as 'adolescent rebellion'. The paradoxical 'I need you to know that I don't need you' reveals the still very asymmetrical dependency relation in which adolescents stand to 'grownups'.

\section{Circumstantial transition}

Understanding the importance of mirroring responsiveness, and an awareness that people's need for this continues in evolving form through childhood into adulthood, can help us to think about the impact on students of being plunged into an unfamiliar environment. Many students arrive at university in a strange town or city and for the first few weeks feel that they exist in a vacuum - they send out signals about themselves, and feel that these vanish into a void, leaving them devoid of the mirroring feedback they need. They are often amongst peers who also are very insecure and not in any state to be giving meaningful attention to others, so they can feel very alone in the crowd. Their geographical surroundings are new so they do not have the comfort of familiar worn paths and their own familiar reactions to these. They often feel that they are, in relation to their courses, completely anonymous until they have begun to get feedback and assessments. In large classes they are often not known by anyone, and sometimes no-one even knows their name. If anyone is left in a void for too long, it starts to have a paralysing and devastating effect on their functioning.

Students need to discover a sense of contingent influence on their new world. They learn about themselves, in this learning environment, by emitting signals in order to trigger these essential resonances which they need to take back in. They need to know how their world responds to them in order to know how to manage and respond to it - to know what their world wants them to be. They need feedback about what they are doing, how they are doing, what they are like, and what others expect of them. But there are difficulties about feedback.

\section{Baggage}

Freud noticed how patients often experienced him, the analyst, as though he were someone else, often the patient's parent (see, for example, Freud, 1920: 291-292). Similarly, a student's experience of you sometimes has little to do with how you are, and they may be impervious to your responses to them if their relationship with you is affected by this phenomenon which Freud termed 'transference', whereby the person unconsciously distorts your reactions and perceives you as if you were someone else. 
In this way students frequently come with baggage about authority figures - experiencing them as if they were teachers, parents or others from the student's past. This transference may be idealizing, demonizing, or anything in between. They may expect us to be pressurizing or critical, or at the other end of the scale, inattentive, indifferent, and with no expectations of them at all. Or they may try to make us into an idealized perfectly attentive and comforting parent whom they felt they never had.

Students expect to be judged by academic staff, by virtue of the teacherstudent relationship, and this resonates with pressures and expectations from the past. While students do have to submit themselves to academic scrutiny, they can be helped to disentangle this from the personal judgement, anxiety or criticism they so often fear. It is helpful for them to discover that we can be aware of them and think about them without worrying about them or needing things of them in the same way that their parents do or did. (This gets slightly complicated by the reality that staff do worry about whether we can get them through our courses!) As teachers and support staff, we can often be more effective if we can help them to differentiate us from the ghosts and spectres of their pasts.

\section{Contagious anxiety}

A common example of baggage which many people carry is the worry that their problem will be 'too much' for those around them, which is very often a factor in turning to a counsellor. Often parents' protective anxiety has diverted the focus of parental attention away from the reality of a child's difficulty and what can or cannot be done about it, and parents have been preoccupied instead by their own worries about their child. Some children come to believe that it's best to hide their problems, because they think parents will just 'fuss' if they try to turn to them for support, i.e. the child thinks the parent will be hurt by or dismissive of the child's problem, and unable to attend to it. Adolescents often feel this way. So their assumptions about available adult responses to them in turn flavour the way they communicate their needs, and at times become self-fulfilling.

If they have abandoned any attempt to address their pain through dialogue, people sometimes 'act out' their internal distress in behaviour such as self-harm, excessive substance use, eating difficulties, or by isolating themselves and cutting off everyone and everything. Students often tell us that they do this because they feel it would be useless or unsafe to express their feelings directly to anyone. The extreme behaviour has become the only way they know of expressing how they feel either to themselves or others: by showing rather than telling. Their distress often contains anger and despair - the behaviour often aims to give others the hurt they are 
feeling inside themselves, making others feel it too. 'Acting out' behaviour very effectively transmits (in psychoanalytic terminology this is "projection') acute feelings into other people - who are then put in the position of having to deal with their own intense reactions, which may feel anxious, angry and panicky. But what people need when in these intense states, as much as possible, is a calm response which is not reactive or retaliatory.

Discovering that someone can know about their difficulty without being overwhelmed is in itself very helpful. Simply being known and known about may often be much more important than the advice or help which the knowledge may prompt us to give. This is because a student's discovery that you are not panicked or overwhelmed by his or her problems enables her or him to learn that maybe he or she can be less overwhelmed by them, and this frees her or him to get to know it better, and to mobilize his or her own coping responses and find his or her own solutions. So - paradoxically - wheeling out the supportive heavy artillery can actually be more alarming than helpful to someone who is already anxious about the scale of their disaster.

Again this is a continuation of a fundamental infancy developmental process, whereby intense sensations and impulses lead a baby to behave in emotive ways (a cry or a smile) which very effectively project intense (e.g. pleasurable or anxious) feelings into caregivers, who then have the job of not being overwhelmed or distracted by the feelings set off in them, but 'containing', making sense of, or in a Kleinian-Bionian framework, metabolizing the signals (see, for example, Mitchell and Black, 1995: 102-108) and responding appropriately. The baby thus enlists and engages the caregiver in a dyadic processing and regulating of the baby's states, which gradually become integrated into patterns that can be tolerated, recognized, thought about, coherently responded to, and represented in the minds and language of caregivers. As caregivers also reflect these thoughts, recognitions and responses back to a baby, the baby gradually takes them back in and builds them into a constellations of internal 'working models' (Bowlby, 1969). Through experiencing - in good circumstances - this process of securely and even pleasurably existing and having an impact in another's world, the baby develops internal tools for regulating his or her own states. Thus as well as getting things happening by her or his behaviour, what the baby gets back is both the happening things, and also some recognition and feedback about how she or he gets things happening, thrown in with the package like compound interest. When this mechanism is functioning well, there is a developmental trend towards self-regulation.

In asymmetric dependency relationships like parenting, teaching and counselling ones there is a perennial question about how to give help which can be used by someone to reduce their need for further help. We 
have to monitor whether help is being helpful or not, and it is sometimes difficult to balance the helpfulness of help against help's disabling spinoff. Students who can regulate and manage things well already will be better at digesting help and sorting out the wheat from the chaff for themselves. These will be people whom it feels easy and comfortable to help. People with more fragile self-regulatory resources will present as needier but also be more vulnerable, they will swallow without being able to chew, and so ingest things in less nourishing more toxic form - with easily upset psychic stomachs. They may seem to need more, but they may also react to their own neediness as a sign of inadequacy, and to any offer of help as a confirmation that we too see them as inadequate, thus compounding their passivity and stuckness. These needy students are often resistant to responsiveness, distorting their perception of its meaning, and so also need help to smooth out their experience of being offered help enough to take it in. For such people, our response has to enable a change and an acceptance of an unfamiliar view of themselves in interaction with others. We have to have the courage to challenge their status quo. Even so, sometimes people's capacity to use help is so disturbed that it becomes almost impossible to offer anything useful.

\section{The bottomless pit}

The discovery that someone will actually listen does sometimes open floodgates, and a student will become very demanding, almost as though any amount of attention and help is not going to be enough. They have not had a chance to get the thermostat on their self-regulation mechanism set up effectively. This may happen when the student still internally experiences the present as though it were inevitably repeating the past, perhaps in terms of a deficit of acceptance, safety or responsiveness which meant that their states never were very coherently regulated. Their dark-tinted spectacles make it impossible for them to perceive undistorted - or trust in the reality of - what you are giving. They remain highly alarmed by their own state, no matter what you do.

Sometimes you can come to feel that you are the only person that a student can be helped by, and that it is vital that you somehow get it right. The student's singling out of one rescuer whom they latch onto in this way is a sign that the student really is needy, but also unable to take in successfully what is being given, hence the escalating demand for more. Seeking out one willing individual may be a way of warding off anticipated wider rejection or criticism, making it hard for you to say 'no'. But this student is not effectively using the help, and the help is not reducing or resolving their sense of need. 
When a student has invited you into this role, it is likely to be a signal of major difficulties which cannot be solved simply, and certainly not by any one person. What they most need to do is develop their capacity to take in, digest and use support more effectively. This might be a major aim of a therapeutic relationship with a counsellor, but people who have a very fragile capacity to take in help are often the ones who are most ambivalent about seeking or persisting with counselling or therapy, so the most chaotically troubled students are often in more contact with academic or hall staff with whom they already have a relationship. They may be extremely resistant to counselling, and occasionally need psychiatric intervention. But for the majority of students who need help, the outlook is much more positive.

\section{Student 'problems': pathological or developmental?}

'Past trauma' or 'developmental deficit' models for understanding problems have been criticised for being reductionist and pathologizing (Mitchell, 1988a). An alternative view is that problems, wherever we locate them in the spectra of dysfunctionality we choose to apply to them, are common or even ubiquitous, and except for very severe misfortunes or very selfdestructive personality disorders, problems frequently carry the seeds for onward change and growth. The developmental processes we are in the habit of assuming to have been stopped in their tracks by childhood environmental deficits or traumas are often very much alive in new incarnations in the present, so that, for example, a person's self-building mechanism is always, throughout life, sending out feelers for newly helpful reflective feedback.

The interpersonal environment plays a continuous, crucial role in the creation of experience. The earliest experiences are meaningful not because they lay down structural residues which remain fixed, but because they are the earliest representation of patterns of family structure and interactions which will be repeated over and over in different forms at different developmental stages. Understanding the past is crucial, not because the past lies concealed within or beneath the present, but because understanding the past provides clues to deciphering how and why the present is being approached and shaped the way it is. (Mitchell, 1988b: 149)

While the constructing process may be particularly elastic and rapid in infancy, most of it does not stop there, and as the complexity of the mechanism develops, so does the array of uses it is put to. Adolescents are on the lookout for responses which they can use to expand their selfknowing and self-managing repertoire, at a time of life when horizons 
rapidly expand. It is usual for adolescents to be hungry for access to new sorts of responses from new adults in their world which are different from the patterns they have grown up with. Students take themselves to university, and they are looking for things not provided by the family world they have inhabited up to now. Since staff are the 'grownups' on their newly erected stage, staff will be players in their developmental drama, and we can expect that at times this will include dynamics which have the flavour of friction, grit, struggle, or the appearance of 'problems'.

\section{Who should respond?}

Academic staff want guidance about student support issues. Where does the limit of their responsibility lie? At what stage does student neediness become a 'welfare' issue which passes beyond their personal capacity or competence? Who does pick up where they leave off? How does institutional 'duty of care' really work (Harris, 2003)? In the context of widening participation as well as higher education fees, the climate of student needs and demands is shifting radically. Academic staff want recognition of the fact that their teaching role seems to be becoming simultaneously a welfare role, as students with complex needs increase in numbers while at the same time the onus to recognize and respond to student needs is increasingly taken on by institutions.

A proliferation of specialist support services is one response to this situation. But fragmented and parcelled off responses leave some needs, especially those around issues of self-integration, at risk of being unmet. Perhaps this is why we find ourselves puzzling at the fuzzy overlap between counselling, academic support, disabilities support, chaplaincy support or mental health intervention. Students' needs do not really divide vertically - those who have serious difficulties often turn to multiple sources of support.

Support at the 'point of delivery' (Layer et al., 2002) via existing relationships with academic staff has many advantages. Students' use of mainstream academic guidance, teaching and support can have major therapeutic or developmental effects beyond the academic focus from which it may originate. The majority of students will get much more from their three or more years of relationship with academics than they do from specialist 'problem-oriented' support services (see, for example, O'Carroll's discussion of students' dynamic relationship to the institution, 1997).

A cybernetic systems analogy can be applied to the question of when a problem requires specialist help, rather than being resolvable from within the context in which it arises. There is a threshold between states in which input is used by the system to keep it within a stable range, and states in 
which input plus processing result in an unsustainable feedback cycle which takes the system on a trajectory towards self-destruction. Also unsustainable can be situations where a foreign toxic input is too damaging for the system to be able to recover unaided (a mosquito bite can be dealt with where a snake bite might be fatal). There comes a point where specific 'therapy' is called for - something corrective from outside the system, and sometimes even that is not enough. A rule of thumb question might be: can a student use one's offerings to keep their developmental momentum on track, or are one's interventions ineffective or even impeding?

\section{Concluding comments}

Teaching and support can be jointly understood as fuel for students' learning development in an 'emotionally literate' sense (Park, 2004), where academic learning is part and parcel of personal learning about how one works and how to work oneself, a process in which the capacity to make mistakes, get stuck, and be curious about one's problems - personal or academic - is a prerequisite for growth, and is intrinsic to the capacity for success.

It has been the suggestion of this article that a psychodynamic perspective can make a useful contribution to forming an integrated understanding of students' problems and need for help. It has described how a fundamental part of studenthood is the process of negotiating the interface between the self a student brings with him or her, and the novel signals, demands and meanings of this very new environment and stage of life. The academic process of being helped to learn takes place within the broad personal developmental process sketched out above, so academic staff, as well as support staff, become recruits into students' wider developmental task. Just as infants do at the earliest formative stages of life, students use responsiveness and feedback from the environment around them to manage, understand and grow from the challenges they engage in.

According to a psychodynamic view, 'problems' and 'help' within relationships function as the catalytic agents of needed change. Teachers, peers, and support staff all exist in relationship to students, and it is these relationships which - especially for the less secure - can powerfully and crucially contribute to someone's capacity to manage and metabolize the disorientation and discomfort which their learning and growth often entails. Simply to hold up a mirror to the as yet undiscovered parts of someone's self is not enough, unless we can at the same time help them to manage their puzzlement at what they see. If they can hold their nerve and bear to go on looking, they will begin to construct meaning from the disjunction 
between the self they thought they knew and the image they begin to recognize in the reflection they see in front of them.

\section{References}

BOWLBY, J. (1969) Attachment and Loss. London: Pimlico.

FONAG Y, P. (2001) Attachment Theory and Psychoanalysis. New York: Other Press.

freud, S. (1920) 'Beyond the Pleasure Principle', in A. Richards (ed.) On

Metapsychology, pp. 269-338. London: Penguin (The Penguin Freud Library ii).

GERHARDT, S. (2004) Why Love Matters: How Affection Shapes a Baby’s Brain. Hove:

Brunner-Routledge.

HARRIS, P. N. (2003) 'Students, Mental Health and the Law'. School of Law,

University of Manchester.

holmes, J. (1996) Attachment, Intimacy, Autonomy: Using Attachment Theory in Adult Psychotherapy. Northvale, NJ and London: Jason Aronson.

layer, G. A., SRivastava, T. L. \& yorke, M. (2002) 'Student Success: Building

for Change', in Student Success. Action on Access report for HEFCE and the Learning and Skills Council: http:// www.actiononaccess.org/resource/aoadocs/ssrep3.doc [accessed 26 July 2005].

Mitchell, S. A. (1988a) 'Clinical Implications of the Developmental Tilt', in Relational Concepts in Psychoanalysis: An Integration, pp. 151-72. Cambridge, MA: Harvard University Press.

Mitchell, S. A. (1988b) ‘The Metaphor of the Baby', in Relational Concepts in Psychoanalysis: An Integration, pp. 127-50. Cambridge, MA: Harvard University Press.

MitChell, S. A. \& BLACK, M. J. (1995) Freud and Beyond: A History of Modern Psychodynamic Thought. New York: Basic Books.

O'CARRoll, L. (1997) 'Psychodynamic Counselling in an Educational Setting: Containing, Transference and Clientele’, Psychodynamic Counselling 3(3): 303-20.

PARK, J. (2004) 'Unblocking the Learning Blocks'. Public Lecture, June, University of Portsmouth.

PERCY, A. (2001) 'Student Induction: The Psychology of Transition', in P. Frame (ed.) Student Induction in Practice, pp. 95-104. Birmingham, Staff and Educational Development Association Paper 113.

stokoe, P. (2004) 'The Containing Institution: Some Thoughts About Setting Up and Maintaining a Containing Environment'. Keynote Address, Annual Conference of the Association for University and College Counselling, June, University of Leicester.

\section{Biographical note}

AMANDA BAKER is a counsellor in the Counselling Service of the University of Portsmouth.

Address: University Counselling Service, Department of Curriculum and Quality Enhancement, The Nuffield Centre, St Michael's Road, Portsmouth PO1 2ED, UK. [email: amanda.baker@port.ac.uk] 